\title{
El tema del viaje en la literatura infantil*
}

ste trabajo busca analizar el tema del viaje en la literatura infantil a partir de la $\checkmark$ perspectiva de la formación del lector, como reflejo del recorrido de construcción del personaje. La discusión de este tema está hecha a través del análisis del cuento de hadas «Piel de Asno», publicado por primera vez por Charles Perrault (1694) y de una obra de literatura infantil brasileńa: Sua alteza, a Divinha (Su alteza, la Divina), de Ângela Lago (1990).

Siempre que buscamos caracterizar el género infantil, siempre que buscamos sus fuentes, llegamos a las narrativas de tradición oral popular — los llamados cuentos de hadas-. Son éstas, seguramente, las primeras y mejores historias que componen el patrimonio de lo que hoy conocemos como literatura infantil, género que carece de mayores definiciones y conceptualizaciones que atiendan la inmensa gama de variantes que surgen sobre este rótulo.

Los cuentos de hadas, como precursores del género infantil, resultan de un movimiento, en el cual se insertan al viaje: el viaje de la palabra y de la voz. La teórica Nelly Novaes Coelho (2003), a propósito de los cuentos de hadas, menciona la «difusión realmente espantosa» de esas historias en tiempos pasados:

\footnotetext{
Traducción del portugués de María Luisa Vásquez Castañeda.
} 
[...] cuando recordamos que, en esos tiempos primordiales, la comunicación se daba de persona a persona y los pueblos que recibían tales narrativas vivían distanciados geográficamente, separados por montañas, ríos, mares, en un tiempo en que los viajes eran hechos a pie, o a caballo o en barcos toscos [...]. Eso prueba la fuerza de la Palabra como factor de integración entre los hombres. (Coelho 2003: 31)

La palabra a la que se refiere la autora es la presencia viva de la voz humana, realizada en beneficio a desencadenar el proceso de proyección y mantenimiento de la memoria; asimismo, asegura también (y principalmente) la propagación de la cultura. Según Paul Zumthor, el gran compromiso de las obras es la voz.

Los cuentos de hadas son, por tanto, «viajeros», y su interminable viaje es también la garantía de sobrevivencia. Como narrativas monológicas, esos cuentos sólo se actualizan gracias al diálogo en la medida en que se mueven de un punto a otro, en el espacio geográfico de las diferentes culturas que de ellas se apropian y en las diferentes versiones dadas a esas narrativas (dentro de un mismo país, de un autor para el otro).

La permanencia garantizada por el movimiento y por el cambio (que son esencialmente características del viaje) también revela un movimiento sustentado por las narrativas de tradición oral: el encuentro del yo con el otro que es lo que vuelve posible el encuentro consigo mismo.

El psicoanálisis se dirige a los cuentos de hadas como fuentes de investigación acerca del funcionamiento de las capas más profundas de la mente humana. Uno de sus más reconocidos estudiosos, Bruno Bettelheim, afirmó la importancia de esas historias (los cuentos de hada) para la constitución de lo self, que implica la construcción — por el individuo - de un sentido para vivir. Según el psicoanalista, el desenvolvimiento del sentido de la vida pasa por el entendimiento que el individuo va teniendo de sí mismo, lo que lo vuelve más apto a entender también a las otras personas y al mundo.

Las lecturas literarias, entendidas aquí como experiencia y ejercicio de la alteridad - porque nos presenta a otro a quien miramos y nos reconocemos en él_ posibilitan la construcción de una identidad y, por tanto, se constituyen — por su naturaleza - en un camino o, metafóricamente, en un viaje de formación.

Tzvetan Todorov en El viaje y su relato pregunta y responde: «¿Qué es lo que no es un viaje? Por lo menos que se dé un sentido figurado de este término - y jamás podemos 
dejarlo de hacer—, el viaje coincide con la vida, ni más ni menos: ¿Es el que está, más allá de un paso del nacimiento a la muerte?» (2001: 95).

Curiosamente los personajes de los cuentos de hadas frecuentemente viajan y, en cuanto viajan, se constituyen como personajes —en su recorrido de crecimiento y de desenvolvimiento (en general comienzan pobres o infelices y llegan al final bien realizados material y emocionalmente) — y como referencias de un proceso de formación para el lector. Podemos decir, entonces, que en algunos o muchos cuentos de hadas, el viaje funciona como elemento constitutivo del proceso de construcción del personaje, tanto en el nivel de la historia como en el nivel del discurso ficcional.

\section{La lectura y la formación del lector}

Igária Matos, recordando a Paul Ricoeur, formula la siguiente afirmación:

La lectura es la práctica más noble de la educación humanística, proveedora de paciencia y de conciencia no sólo por trabajar nuestros miedos y nuestras esperanzas, sino también por su dimensión ética por lo tanto, «¿Qué sabríamos nosotros del amor y del odio, de los sentimientos éticos, y en general de todo lo que llamamos de sí mismo si todo eso no hubiese pasado al lenguaje, articulado por la literatura?», pregunta Paul Ricoeur. (2006: 16)

Las discusiones sobre el género infantil, en general, pasan por la cuestión de la lectura y de la formación del lector. Tal vez porque ya hay un tiempo en que la enseñanza de la lectura se inicia por medio de los textos llamados «infantiles» o de una producción destinada (deliberadamente destinada) al niño lector. De manera general, lectura y lector tienen constituidos áreas recurrentes de investigación. João Alexandre Barbosa, al tratar de la enseñanza de la literatura, lo sitúa entre la lectura y la crítica literaria. Según este autor: «Pocas épocas han asistido a un debate tan cerrado al respecto del propio estatuto del lector y de la lectura cuanto la nuestra» (Barbosa 1996: 60).

La diferencia queda por cuenta de que hoy, lectura y lector no son apenas «objetivos finales de la obra [...] sino instancias de estructuras de la propia obra». La lectura se vuelve, entonces, elemento representativo de la invención literaria.

Los estudios más recientes acerca del género infantil apuntan a la importancia de la inscripción del lector (de varias maneras) como elemento estructurador de la obra y condición 
para que la literatura infantil afirme sus estatutos de arte. La obra como ejercicio de diálogo con el lector, ahora considerado no sólo el destinatario de enseñanzas morales, sino responsables por el rellenado de los intervalos del texto, de que resultan sus sentidos más profundos. La lectura literaria vista, entonces, como hábito personal y no como mera práctica educativa, aunque actúe mucho como elemento de formación y humanización.

Ya afirmamos en otro trabajo que es notable la cantidad de títulos contemporáneos de literatura infantil que retoman la narrativa tradicional. Los resultados son variados, pero nos interesa aquí recordar la fuerza del clásico como fuente de nuevas creaciones, ya que sirve de soporte o sustenta la relectura.

Ítalo Calvino afirma que «un clásico es un libro que nunca terminó de decir aquello que tenía para decir» (1995: 11). Asimismo, sostiene que la experiencia de lectura de los clásicos es formativa porque da «una forma a las experiencias futuras, abasteciendo modelos, recipientes, términos de comparación, esquemas de clasificación, escalas de valores, paradigmas de belleza: todas, cosa que continúan valiendo aunque nos recordemos poco o nada del libro leído en la juventud» (1995: 10).

El cuerpo escogido para este trabajo se compone de títulos representativos de ese movimiento: un cuento de hadas y un título contemporáneo que retoma elementos de narrativa tradicional.

\section{El viaje como metáfora de la lectura y del proceso de} formación del lector

Dublicado por la primera vez en 1694, el cuento «Piel de Asno» continúa integrando las
antologías de narrativa maravillosa. Es cierto que su popularidad no se compara a la de «Caperucita roja» o «Cenicienta», pero eso puede ser explicado por la presencia del tema del incesto, deliberadamente evitado por varias ediciones de cuentos de hadas destinadas a las lecturas de los pequeños.

El cuento «Piel de Asno» cuenta la historia de un rey que, habiendo perdido a su esposa, decide casarse con la propia hija. Ésta rehúsa a la intensión del papá y huye (con la ayuda de un hada madrina) disfrazada bajo la piel de un asno. La princesa fugitiva encuentra trabajo y abrigo en un reino vecino y pasa a cuidar a gallinas y puercos, siempre ocultando su verdadera identidad bajo la piel de asno. 
El hijo del rey de aquel lugar ve a la moza cierta vez sin la piel del animal y queda encantado con su belleza, pasando a padecer de amor desde ese día. Para salvar la vida del príncipe, los reyes, sus papás, deciden hacer lo que fuera preciso, mostrándose dispuestos a atender a cualquier pedido que el hijo les haga. El pedido del príncipe es simple, pues pide que Piel de Asno haga una torta con sus propias manos para que coma él. Piel de Asno hace la torta y durante su preparación deja caer en la masa un anillo. Al encontrar esto dentro de la torta, el príncipe manifiesta su deseo de casarse con la moza de aquella joya, que pasa hacer probada por todas las mozas del reino. Finalmente, el anillo coincidió con Piel de Asno y los dos se casan en una gran fiesta.

Nos interesa focalizar el movimiento del personaje principal (la princesa Piel de Asno), su salida del reino donde nació y se crió. Piel de Asno es bella, virtuosa y dotada de cualidades que la vuelven prácticamente perfecta y es por eso que necesita partir. Esta condición, al contrario de garantizarle la tranquilidad y una vida sosegada, la empuja al movimiento y a la experiencia de sufrimiento por la conquista de la autonomía (entendida aquí como la capacidad de sobrevivir por sus propios recursos y, así, actuar en relación a su destino). La manifestación de los dotes en el personaje revela su fase de desenvolvimiento, su aproximación de la edad adulta, y la necesidad de construir una conciencia de sí que se revela en contacto con el otro que la percibe.

$\mathrm{Al}$ asomar como mujer, apta para atraer las atenciones de un hombre, se ve obligada a romper los lazos con el lugar donde nació su papá. El ambiente seguro de casa es cambiado (no obstante a la rebeldía de su voluntad) por la inseguridad del viaje, de la deriva, del camino en busca de un nuevo lugar para vivir. Es en ese recorrido que se hace Piel de Asno: busca en varios reinos condiciones para alojarse, trabajar y sobrevivir, hasta que encuentre uno que de cierta forma ella escoja y que también la acoja.

En ese nuevo lugar, Piel de Asno pasa a desempeñar otro papel: el de experimentar el trabajo duro, bajo la condición de una apariencia que la encubra hasta el momento en que puede dejar el disfraz para presentarse tal y como es.

La salida de su lugar de origen y su transferencia en dirección a lo desconocido es fundamental para que el personaje se transforme y transfigure sus recursos en motivos para su felicidad y no para su martirio.

Para el viaje, ella cuenta con la ayuda de un hada madrina, que es quien le aconseja huir de casa disfrazada bajo una piel de asno. Es también la madrina quien provee a la princesa para el recorrido de un equipaje que la acompaña — mágicamente — por debajo de la tierra. 
Hasta poder valerse por sus propios recursos, el personaje cuenta con el auxilio de ese su doble femenino-mágico, sensitivo y místico.

En el caso de Piel de Asno, es el viaje que la coloca delante de la perplejidad existencial y la mueve en dirección de encontrar el sentido de la existencia. En ese sentido, el viaje se vuelve metáfora del proceso de maduración en que el personaje pasa de una etapa ingenua a otra más madura. $\mathrm{Al}$ acompañar en ese recorrido por medio de la lectura, el lector experimenta también esa perplejidad, emprende el viaje metafórico, no por el impacto psicológico que el texto puede causar, sino porque esos cuentos, «como todas las verdaderas obras de arte, poseen una riqueza y profundidad variadas que trascienden de lejos lo que el mismo examen discursivo más cuidado puede extraer de ellos» (Bettelheim 1980: 27).

Sua Alteza, a Divinha, contada por Ângela Lago, publicada en 1990, es una narrativa de tradición oral, rescatada por la autora del mismo modo que gran parte de sus libros. La autora desarrolla un trabajo de rescate de historias populares, presentándolas por medio de proyectos gráficos muy bien cuidados. Es el caso de esta obra que integra imagen, ilustración y textos en un trabajo compuesto con el auxilio del microcomputador.

La página inicial, hecha en papel vegetal, es transparente y permite la visualización del movimiento que puede ser o significar ya sea tiempo (sol y luna), historias en el tiempo o relatos contados por diferentes personas. Un grillo, impreso en el papel vegetal, migra de un lado para el otro conforme el lector mueve la página.

Los recursos inscritos en el texto, aparentemente actuada entre sí, para contar la historia - la sugestión de la voz en presencia espectacular y el microcomputador que dispensa la presencia física en el acto de la comunicación — son aliados competentes en ese trabajo que coloca lado a lado lo antiguo con lo nuevo, también como metáfora del rescate de la tradición por la contemporaneidad (este, también, es un viaje).

Contador y oyente (o lector) participan del mismo ambiente y del viaje emprendido por Louva-a-Deus (Alaba-a-Dios), un joven que resuelve aceptar el desafío de vencer una prueba para casarse con una princesa. El desafío consiste en resolver tres adivinanzas que la princesa le formule, al mismo tiempo que él le formule tres que ella no adivine.

Es durante el viaje y a partir de las experiencias que viven a lo largo del recorrido que Louva-a-Deus consigue componer las adivinanzas que dirige a Divina. Como la solución de estos enigmas están en su propia experiencia y en su propio recorrido, Divina no consigue resolverlos. Es en la confrontación con el enigma del otro (particular porque individualmente es construido durante el viaje) que Divina se libera de la obsesión de adivinar siempre todo. 
Y es a partir de ahí que ella adquiere las condiciones de convivir con algo que no conoce completamente, o sea, condiciones para el ejercicio de la alteridad.

Louva-a-Deus consigue responder correctamente las preguntas formuladas por la princesa por pura suerte. Son coincidencias extremas y hasta muy graciosas, el resultado de su gran suerte permiten al personaje dar respuestas consideradas ciertas por Divina.

El texto es marcado por el humor que congrega gente alrededor de la historia. A lo largo del libro se van juntando más y más oyentes a la medida que el personaje Louva-a-Deus va progresando en su tarea. Son representantes de las más diferentes clases sociales (desde reyes hasta campesinos), además de animales, los que acaban por dar un carácter figurativo a toda la historia.

No todo el libro está escrito. Hay palabras que son substituidas por figuras, recursos que convocan al lector a la participación y que adicionan al texto un carácter de adivinaciones, al igual de como sucede a los personajes de la historia.

Así, el recorrido del viajero lo cumple él —el lector y la narrativa — como materia de memoria que viaja para sobrevivir, y sobrevive porque instaura un sentido a través del ejercicio de la lectura. 


\section{BIBLIOGRAFÍA}

Barbosa, Joao Alexander

1996 A biblioteca imaginária. São Paulo: Ateliệ Editorial.

BeetTelheim, Bruno

1980 A psicanálise dos contos de fada. Río de Janeiro: Paz e Tierra.

Calvino, Ítalo

1995 Por que ler os clássicos. São Paulo: Companhia das Letras.

Coenlo, Nelly Novaes

2003 Conto de fada: mito, simbolo, arquétipo. São Paulo: DCI.

LAGO, Ângela

1990 Sua Alteza, a Divinha. Belo Horizonte: RHJ.

Matos, Olgária

2006 Discretas esperanças. Reflexóes filosóficas sobre o mundo contemporâneo. São Paulo: Nova Alexandria.

Perrault, Charles

2004 "Pele de Asno». Tradução de María Luiza X. de Borges. En TAtar, María (org.). Contos de fadas. Río de Janeiro: Jorge Zahar.

Todorov, Tzvetan

2006 "A viagem e seu relato». Tradução de Lea Mara Valezi Staut. Revista de Letras, vol. 46, N. ${ }^{\circ} 1$. 